\title{
EVALUATION OF THE MATERIAL CONSTANTS OF NITRILE BUTADEINE RUBBERS (NBR) WITH DIFFERENT CARBON BLACK (CB): FE-SIMULATION AND EXPERIMENTAL
}

Hassan M. A., Abouel-Kasem A. and Mahmoud A. El-Sharief

Mechanical Engineering Department, Faculty of Engineering Assiut University, Assiut, EGYPT 71516

(Received, November 2, 2009 Accepted December 1, 2009).

Carbon black $(C B)$ is used to enhance the mechanical properties of nitrile butadiene rubber (NBR) compounds compared with unfilled compounds. Rubber component design has remained a tedious work because of poor material models inadequately representing hyperelastic and viscohyperelastic behaviour. However, an appropriate choice of material constants can enable predicting elastomeric deformation sensibly and thus make well designed rubber products economically. In this paper, the experimental mechanical properties of NBR with different carbon black loading, CB, have been determined through, tension, compression and relaxation tests. Nonlinear mechanical behaviors of rubbers are described by strain energy functions in order to guarantee that the rigid body motions play no role in the constitutive law. The mathematical material models are based on the existence of strain energy density functions, $W$, to be scalar potential that depend on the component of the right Cauchy-Green deformation tensor or Green's strain tensor. The experimental data are fitted to these models in order to find the rubber material constants. Viscohyperelasticity behavior is generated by fitting the experimental data provided by the standard quasi-static tests (tensile, compression) to determine the material constants, while the standard relaxation tests are used to obtain the scalar multipliers and relaxation time constants. Study of the material constants based on different strain energy density functions is carried out. A comparison between experimental load/displacement response and FE-analysis of uniaxial compression test at different $C B$ loading is presented.

KEYWORDS: Rubbers, Carbon black, Material properties, Material models, hyperelastic and viscohyperelastic behavior, FES

\section{INTRODUCTION}

Viscoelastic deformation consists of three components: elastic, high elastic and viscous. Different models with discrete set of elastic modulii and relaxation times can successfully represent the viscoelastic behavior of many materials. Generalized Maxwell model has great capabilities in representing the nonlinear viscoelastic behaviors. Milašienè et al. [1] studied stress relaxation in laminated leather in order to provide the possibility to investigate the time dependence shown by different system layers of laminated leather and understand their viscoelastic behavior. The generalized 
Maxwell model which possesses a regular spectrum of relaxation times that successfully describes stress relaxation behavior of the leather in non-linear regions was adopted. Abouel-Kasem and Lazarev [2] investigated micro viscoelastic model, of rubber used in the numerical analysis and design of machine parts. It was found that the relaxation and creep behaviors of the rubber material were successfully represented by the generalized Maxwell model. Fujii [3] analyzed the dynamic response of sandwich beams with an adhesive damping layer adopting the generalized Maxwell model to represent the viscoelastic behavior of the adhesive layer.

\section{NOMENCLATURE}

\begin{tabular}{|c|c|c|c|}
\hline $\begin{array}{l}C_{10} \\
C_{01} \\
C_{11}\end{array}$ & $\begin{array}{l}\text { Material constants for } \\
\text { incompressible material model }\end{array}$ & $W$ & Strain energy density function \\
\hline$E(t)$ & $\begin{array}{l}\text { Relaxation modulus for the } \\
\text { generalized Maxwell model }\end{array}$ & $\delta^{n}$ & Time dependent scalar multipliers \\
\hline$E_{i j}$ & $\begin{array}{l}\text { Components of the Green's strain } \\
\text { tensor }\end{array}$ & $\eta_{k}$ & $\begin{array}{l}\text { Coefficient of viscosity of the } \\
\text { Maxwell element }\end{array}$ \\
\hline$E_{k}$ & $\begin{array}{l}\text { Young's modulus for element } \\
\text { number } k\end{array}$ & $\begin{array}{c}\lambda_{1} \\
\lambda_{2}, \lambda_{3}\end{array}$ & Principal stretch ratios \\
\hline$E_{0}$ & $\begin{array}{l}\text { Quasi-equilibrium value of the } \\
\text { modulus of elasticity }\end{array}$ & $\lambda^{n}$ & Associated relaxation times \\
\hline$G$ & Modules of Rigidity & $\begin{array}{c}\mu_{n} \& \\
\alpha_{n}\end{array}$ & Material constants for Ogden \\
\hline $\begin{array}{l}I_{1}, I_{2} \\
\& I_{3}\end{array}$ & Strain invariants & $v$ & Poisson's ratio \\
\hline$J$ & Volumetric ratio & $\tau_{k}$ & Relaxation time of an element $\mathrm{k}$ \\
\hline$K$ & Initial bulk modulus & $\Psi^{\infty}$ & $\begin{array}{l}\text { Elastic strain energy for long term } \\
\text { deformations }\end{array}$ \\
\hline$Q_{i j}$ & Internal variables & & \\
\hline
\end{tabular}

Sato and Toda [4] investigated the peeling process of pressure-sensitive adhesive tapes through adopting a combination of Maxwell elements and generalized Maxwell model. The viscoelastic behaviors of the adhesive material could be represented. According to the above literature, the generalized Maxwell model was successfully used in representing the viscoelastic behavior of different materials. The relaxation modulus for the generalized Maxwell model can be expressed as:

$$
E(t)=E_{0}+\sum_{k=1}^{n} E_{k} e^{-t / \tau_{k}}
$$

where $\tau_{k}$ is the relaxation time of an element $\mathrm{k}, \tau_{k}=\frac{\eta_{k}}{E_{k}}, E_{0}$ is the quasi-equilibrium value of the modulus of elasticity, $n$ is the total number of Maxwell elements, $E_{k}$ is the Young's modulus for element number $k$ and $\eta_{i}$ is the coefficient of viscosity of the Maxwell element. 
Carbon black $(\mathrm{CB})$ is used to enhance the mechanical properties of nitrile butadiene (NBR) rubber compounds compared with unfilled compounds. Rubber component design has remained a tedious work because of poor material models inadequately representing hyperelastic and viscohyperelastic behaviour. However, an appropriate choice of material constants can enable predicting elastomeric deformation sensibly and thus make well designed rubber products economically.

In this work, the nonlinear mechanical behaviors of rubbers are described by strain energy functions in order to fit the experimental mechanical properties of NBR with different carbon black loading, $\mathrm{CB}$, that have been determined through, tension, compression and relaxation tests. Seven material models based on the existence of strain energy density functions are used to find the rubber material constants. Viscohyperelasticity behavior is generated by fitting the experimental data provided by the standard relaxation to determine relaxation time constants. The choice of material constants when nitrile rubbers and metal surfaces are brought into contact is studied by FE-analysis to allow confidence in hyperelastic or viscohyperelastic models.

\section{Experimental work}

All materials used in this research come from Marceleno Company for Chemical Industry and Trade, Cairo, Egypt. The structure of these materials is as follows:

- Nitrile butadiene rubber (NBR).

- Acrylonitrile content of $33 \%$, with specific gravity $0.990 \pm 0.005$ and Moony viscosity (ML4) of about 45 at $373 \mathrm{~K}$

- Fast extruding furnace black (FEF) N550 (ASTM designation) with average particle size 40-48 mm (ASTM D 1765-86) and 40-49 $\mathrm{m}^{2} / \mathrm{g}$ average specific area (ASTM D 1765-96).

- MBTS is mercapto benzothiazyl disulfide was used as accelerator.

- DPG is diphenyl-guanigine.

- Other standard rubber compounding ingredients such as stearic acid, zinc oxide, processing oil and sulfur were of commercial grades.

The samples investigated in this study, were composed of NBR compounded with different concentration of N550 carbon black according to the recipe shown in Table 1. The specimens for tension and relaxation tests have the dumbbell shape with rectangular cross-section of $5 \times 2.5 \mathrm{~mm}$ which stamped out from the compression molding vulcanized disk sample as shown in Fig. 1 (a). Specimens for compression test have the dimensions of $12 \pm 0.5 \mathrm{~mm}$ diameter and $25 \pm 0.1 \mathrm{~mm}$ height as shown in Fig. 1 (b).

The tension test is carried out according to ASTM D 412 standard [5]. Such test method describes procedures for determining the effect of the application of a tension load to soft vulcanized rubber and similar rubber-like materials. A tension test apparatus was designed, manufactured and assembled [6]. The dumbbell specimen gripped from each end by means of two triangular aluminum plates, one of them is connected to the movable head while the other is connected to the load cell. This load cell is made of steel ring with two strain gauges (KYOWA $119.6 \Omega$ with gauge length of $5 \mathrm{~mm}$ and gauge factor of 2.11) attached at both sides to form half Wheatstone bridge. One end of the load cell is fixed in the frame while the other end joined to the 
sample grips as fixed head. The maximum load measuring capacity of the load cell was designed to be $980 \mathrm{~N}$ to increase the sensitivity of the output reading voltage. The load measured by the load cell and extension measured by extensometer are recorded continuously. Fig. 2 shows the stress-strain curves for NBR with different CB loading.

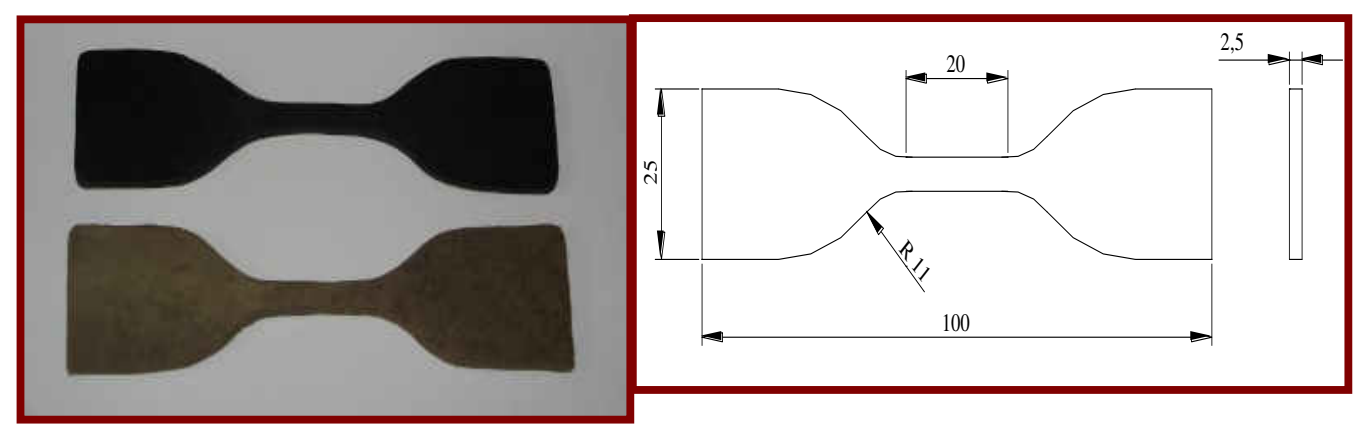

(a) Dumbbell specimen (tension and relaxation tests) (Dimensions in mm)

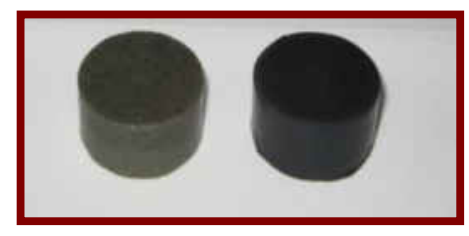

(b) Cylindrical specimen (compression test)

Figure 1 Specimens preparation

Compression test is carried out according to ASTM D 695 standard [7]. A compression test apparatus was designed, manufactured and assembled [6]. The test rig was placed between the moving and fixed heads of a computerized universal testing machine (TINIUS OLSEN digital 100 ton capacity machine). The hard and soft extensometers and load cell signals are transmitted through a shielded cable to a data acquisition system. These signals are recorded with time. Figure 3 shows the compressive stress-strain curves for NBR vulcanizate filled with different CB loading up to $25 \%$ strain. For small compression strain less than 5\%, the stress increases in low rate because the chains is unwound, while at high strain (almost 20\%) the stress is increased in a high rate due to the compression of long chains

The relaxation test is carried out according to ASTM D 674 standard [8]. This test is highly sensitive to small changes in material composition and environmental conditions. A relaxation test apparatus was designed, manufactured and assembled [9]. The dumbbell specimens are gripped by means of two copper rectangular bars connected by means of two bolts, used for upper and lower grips of the specimen. The upper grip is hanged to the load cell (type 546QDT-A5, $2156 \mathrm{~N}$ full capacity, tension and compression, $20 \mathrm{~V}$ input) which is used to determine the stress values continuously as a function of time. This load cell is connected to $20 \mathrm{~V}$ power supply and the output volt was monitored and stored by. Figure 4 shows the relaxation stress as a function of time for NBR vulcanizates filled with different CB loading. 
Table 1 Composition of carbon black filled NBR systems.

\begin{tabular}{|l|c|c|c|c|c|}
\hline \multirow{2}{*}{$\begin{array}{c}\text { Ingredients. } \\
\text { Phr }^{(\boldsymbol{a})}\end{array}$} & \multicolumn{5}{|c|}{ Formula No. } \\
\cline { 2 - 7 } & $\mathbf{N}_{\mathbf{0}}$ & $\mathbf{N}_{\mathbf{1}}$ & $\mathbf{N}_{\mathbf{2}}$ & $\mathbf{N}_{\mathbf{3}}$ & $\mathbf{N}_{\mathbf{4}}$ \\
\hline NBR & 100 & 100 & 100 & 100 & 100 \\
\hline ZnO & 5 & 5 & 5 & 5 & 5 \\
\hline Stearic acid & 2 & 2 & 2 & 2 & 2 \\
\hline Processing oil & 10 & 10 & 10 & 10 & 10 \\
\hline Carbon black & 0 & 20 & 30 & 50 & 70 \\
\hline MBTS & 2 & 2 & 2 & 2 & 2 \\
\hline DPG & 0.5 & 0.5 & 0.5 & 0.5 & 0.5 \\
\hline Sulfur & 2 & 2 & 2 & 2 & 2 \\
\hline
\end{tabular}

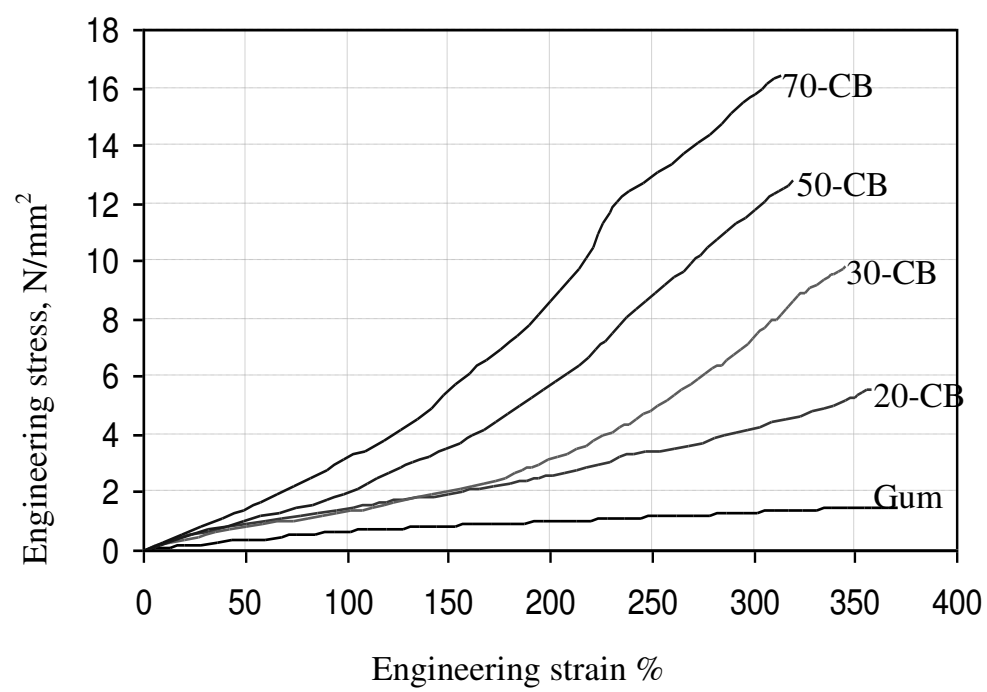

Figure 2 Tensile stress-strain curves of vulcanizates filled with different CB loading.

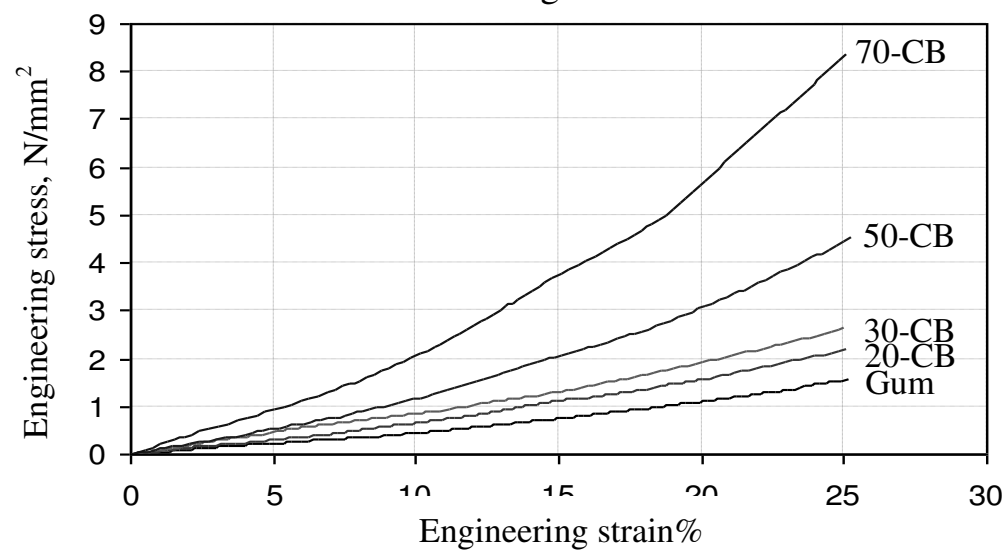


Figure 3 Compressive stress-strain curves of vulcanizates filled with different $\mathrm{CB}$

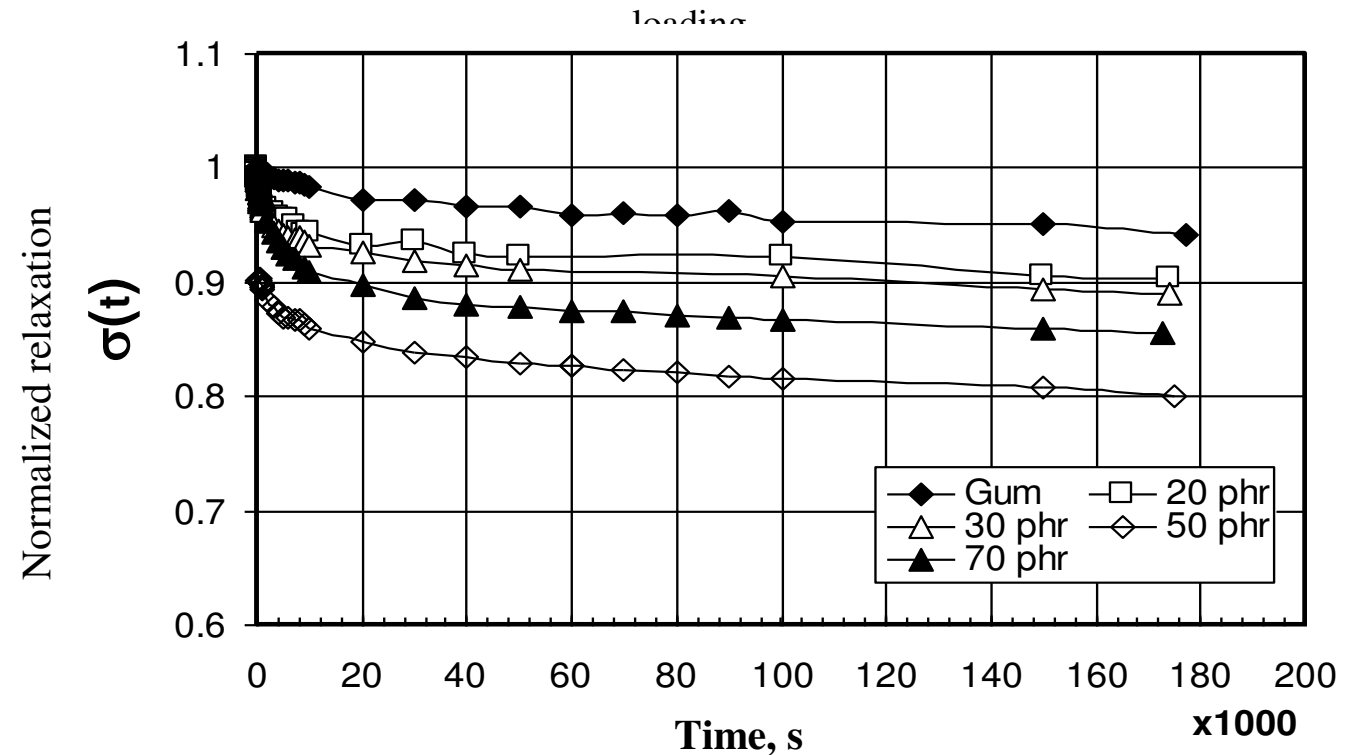

Figure 4 Normalized relaxation stresses, $\sigma(t) / \sigma(0)$, versus time for NBR vulcanizates loading with different $\mathrm{CB}$

\section{Experimental data fitting TO RUBBER material models}

\subsection{Hyperelastic material models}

Materials like rubbers are described by strain energy functions in order to guarantee that the rigid body motions play no role in the constitutive law. Mathematically, this is achieved by postulating the existence of a strain energy density function, $W$, to be a scalar potential, which depends on the component of the right Cauchy-Green deformation tensor or Green's strain tensor. Components of the second Piola-Kirchhoff stress tensor are given by the derivatives of $W$ with respect to the components of the Green's strain tensor. For isotropic hyperelastic material, the strain energy is constant for all orientations of the coordinate axes. Thus the strain energy is an invariant of Green' strain tensor, $E$, and can be expressed as a function of the three principal invariants of $E$ as shown in equation (2) which is known as Mooney-Rivilin model.

$$
W\left(E_{i j}\right)=W\left(I_{1}, I_{2}, I_{3}\right)=C_{1}\left(I_{1}-3\right)+C_{2}\left(I_{2}-3\right)+C_{3}\left(\frac{1}{I_{3}^{2}}-1\right)+C_{4}\left(I_{3}-1\right)^{2}
$$

The constants $C_{3}$ and $C_{4}$ are related to $C_{1}$ and $C_{2}$ as;

$$
C_{3}=\frac{1}{2} C_{1}+C_{2}, \quad C_{4}=\frac{C_{1}(5 v-2)+C_{2}(11 v-5)}{2(1-2 v)}
$$

Where the Poisson's ratio $v=0.49$. The strain invariants $I_{1}, I_{2}$ and $I_{3}$ in terms of the principal stretch ratios, $\lambda_{1}, \lambda_{2}$ and $\lambda_{3}$ are defined as: 


$$
\begin{aligned}
& I_{1}=\lambda_{1}^{2}+\lambda_{2}^{2}+\lambda_{3}^{2} \\
& I_{2}=\lambda_{1}^{2} \lambda_{2}^{2}+\lambda_{2}^{2} \lambda_{3}^{2}+\lambda_{3}^{2} \lambda_{1}^{2} \\
& I_{3}=\lambda_{1}^{2} \lambda_{2}^{2} \lambda_{3}^{2}
\end{aligned}
$$

In equation (2), $C_{1}$ and $C_{2}$ are material constants which must be determined experimentally. For complete incompressibility of the material, $I_{3}=1$. However, Spencer [10] noted that it is not sufficient to set $I_{3}=1$ in equation (2) since certain derivatives of $W$, tend to infinity in the limiting case of incompressibility. This problem is overcome by introducing the arbitrary constants $C_{3}$ and $C_{4}$. Also, in equation (2) it can be noted that the use of $\left(I_{1}-3\right)$ and $\left(I_{2}-3\right)$ ensures that the strain energy is zero when the strains are zeros. This can be easily explained, because for zero strains the principal stretch ratios $\lambda_{1}=\lambda_{2}=\lambda_{3}=1$. In such case, equation (3) reduces to $I_{1}=I_{2}=3$ and $I_{3}=1$.

\subsection{First order Mooney-Rivlin energy function}

Since the constants $C_{3}$ and $C_{4}$ in equation (2) are dependent it can be easily determined if the constants $C_{1}$ and $C_{2}$ are known. Because rubbers are nearly incompressible, the principal stretches in uniaxial test are given by

$$
\lambda_{1}=\lambda_{t}, \lambda_{2}=\lambda_{3}=\frac{1}{\sqrt{\lambda_{t}}}
$$

and the logarithmic stress in axial direction is given by

$$
\sigma_{1}=\sigma_{t}=\lambda_{1} \frac{\partial W}{\partial \lambda_{1}}=2 C_{1}\left(\lambda_{t}^{2}-1\right)+4 C_{2}\left(\lambda_{t}-1\right)
$$

and the corresponding engineering stress is given by

$$
S_{1}=S_{t}=\frac{\sigma_{1}}{\lambda_{t}}=2 C_{1}\left(\lambda_{t}-1\right)+4 C_{2}\left(1-\frac{1}{\lambda_{t}}\right)
$$

where, $\lambda_{t}$ is the stretch ratio in uniaxial test.

The experimental values are substituted into Eq. (4) and solved by means of nonlinear least square method using Lvenberg-Marquradt nonlinear curve fitting algorithm under MARC optimization toolbox (Mentat) [11]. Figures 5(a) and 5(b) shows the curve fitting of experimental data obtained from tension test to first order Mooney-Rivlin model. In order to obtain a good fitting with the experimental data, other models are used as shown in the following equations;

\subsection{Second Order Mooney -Rivlin Energy function}

$$
W=C_{10}\left(I_{1}-3\right)+C_{01}\left(I_{2}-3\right)+C_{11}\left(I_{1}-3\right)\left(I_{2}-3\right)+C_{20}\left(I_{1}-3\right)^{2}
$$

\subsection{Third order Mooney -Rivlin Energy function}

$$
W=C_{10}\left(I_{1}-3\right)+C_{01}\left(I_{2}-3\right)+C_{11}\left(I_{1}-3\right)\left(I_{2}-3\right)+C_{20}\left(I_{1}-3\right)^{2}+C_{30}\left(I_{1}-3\right)^{3}
$$




\subsection{The Signiorini model}

$$
W=C_{10}\left(I_{1}-3\right)+C_{01}\left(I_{2}-3\right)+C_{20}\left(I_{1}-3\right)^{2}
$$

\subsection{The Yeoh form}

$$
W=C_{10}\left(I_{1}-3\right)+C_{20}\left(I_{1}-3\right)^{2}+C_{30}\left(I_{1}-3\right)^{3}
$$

\subsection{Neo-Hookean Material Model}

$$
W=\frac{1}{2} G\left[\left(\lambda_{1}^{2}+\lambda_{2}^{2}+\lambda_{3}^{2}\right)-3\right]
$$

Figures $5(\mathrm{c})-(\mathrm{g})$ show the curve fitting of the experimental data with the above models.

\subsection{Slightly Compressible Energy function (Ogden model)}

In this model, the NBR rubbers are taken to be virtually incompressible and slightly compressible. Such energy function is given by the following formula called Ogden model Eqn. (10).

$$
W=\sum_{n=1}^{N} \frac{\mu_{n}}{\alpha_{n}}\left[J^{\frac{-\alpha n}{3}}\left(\lambda_{1}^{\alpha n}+\lambda_{2}^{\alpha n}+\lambda_{3}^{\alpha n}\right)-3\right]+4.5 K\left(J^{\frac{1}{3}}-1\right)^{2}
$$

where, $\mu_{n}$ and $\alpha_{n}$ are material constants, $K$ is the initial bulk modulus, and $J$ is the volumetric ratio defined by $J=\lambda_{1} \lambda_{2} \lambda_{2}$ where $\lambda_{1}, \lambda_{2}$ and $\lambda_{3}$ are the principal stretch ratios. The order of magnitude of the volumetric changes per unit volume should be 0.01 [10]. Usually, the number of terms taken into account in the Ogden models is $N=4$.

The Ogden model is different from the Mooney-Rivlin model in several respects. The Mooney material model is defined with respect to the invariants of the right or left Cauchy-Green strain tensor and implicitly assumes that the material is incompressible. The Ogden formulation is defined with respect to the eigenvalues of the right or left Cauchy-Green strain, and the presence of the bulk modulus implies some compressibility. For instance, using a two-term series $(N=2)$ results in identical behavior as the Mooney mode if: $\mu_{1}=2 C_{10}, \alpha_{1}=2, \mu_{2}=-2 C_{01}$ and $\alpha_{2}=-2$.

Figure 5(h) shows an example of the experimental curve fitting with Ogden model. It is clear that Ogden, Signiorini and first order Mooney2 give material models best fits; while the fits of the other five models are invariably poor. Therefore, the Ogden material model was chosen to represent the hyperelastic behavior of the NBR and to study the effects of $\mathrm{CB} \%$ and amount of experimental data on material constants of the NBR.

\subsection{Viscohyperelastic material models}


For large strain viscoelastic rubber materials the strain energy function becomes

$$
\psi\left(E_{i j}, Q_{i j}^{n}\right)=\psi\left(I_{1}, I_{2}, I_{3}, Q_{i j}^{n}\right)=W\left(E_{i j}\right)-\sum_{n=1}^{N} Q_{i j}^{n} E_{i j}+\sum_{n=1}^{N} W_{1}^{n}\left(Q_{i j}^{n}\right)
$$

where $E_{i j}$ are the components of the Green's strain tensor, $Q_{i j}$ internal variables and $W$ the elastic strain energy density for instantaneous deformations. The components of the second Piola-Kirchhoff stress are given as:

$$
S_{i j}=\frac{\partial \psi}{\partial E_{i j}}=\frac{\partial W}{\partial E_{i j}}-\sum_{n=1}^{N} Q_{i j}^{n}
$$

Equation (4) can also be written in terms of the long term moduli resulting in a different set of internal variables $T_{i j}^{n}$ as:

$$
\psi\left(E_{i j}, T_{i j}^{n}\right)=\psi^{\infty}\left(E_{i j}\right)+\sum_{n=1}^{N} T_{i j}^{n} E_{i j}
$$

where $\psi^{\infty}$ is the elastic strain energy for long term deformations. Using this energy function definition, the stresses are obtained from Eq. (14) as;

$$
S_{i j}=\frac{\partial \psi}{\partial E_{i j}}=\frac{\partial \psi^{\infty}}{\partial E_{i j}}+\sum_{n=1}^{N} T_{i j}^{n}
$$

The viscoelastic energy function given by equation (13) can also be expressed as Prony series expansion with similar form of each term as;

$$
\psi=\psi^{\infty}+\sum_{n=1}^{N} \delta^{n} W \exp \left(-t / \lambda^{n}\right)
$$

Where $\delta^{n}$ time dependent scalar multipliers and $\lambda^{n}$ associated relaxation times. At time zero (or for time process: $t<\lambda^{n}$ ), the elastic energy of equation (15) reduces to:

$$
\psi(0)=W=\psi^{\infty}+\sum_{n=1}^{N} \delta^{n} W \quad \text { or } \quad \psi^{\infty}=\left[1-\sum_{n=1}^{N} \delta^{n}\right] W
$$

Then the time dependent energy function is given by substitution of equation (16) into equation (15) as:

$$
\psi(t)=W\left[1-\sum_{n=1}^{N} \delta^{n}\left(1-\exp \left(-t / \lambda^{n}\right)\right)\right]
$$

Discussion will be restricted to the case $N=2$ for simplicity hence:

$$
\begin{aligned}
\psi^{\infty}=\left[1-\delta^{1}-\delta^{2}\right] W \\
\\
\psi(t)=W\left[1-\delta^{1}\left(1-\exp \left(-t / \lambda^{1}\right)\right)-\delta^{2}\left(1-\exp \left(-t / \lambda^{2}\right)\right)\right]
\end{aligned}
$$

The energy function, $\psi(t)$ versus time data being used for viscohyperelasticity can be generated by fitting the experimental data provided by standard quasi-static tests, such as tensile and compression, to determine the material constants of the free energy function $(W)$. However, standard relaxation tests are needed to obtain scalar 
multipliers, $\delta_{1}, \delta_{2}$ and relaxation time constants, $\lambda_{1}, \lambda_{2}$. The viscohyperelasticity energy function, given by Eq. (18), is based on a multiplicative decomposition of Ogden model, $W$, for instantaneous deformation and a relaxation function in a Prony series, the terms in square brackets. For different percentage CB the scalar multipliers and relaxation time constants were determined and tabulated in Table 2.

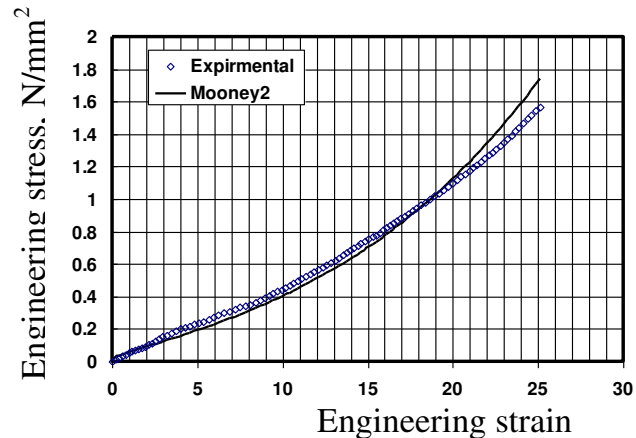

(a) First order Mooney2

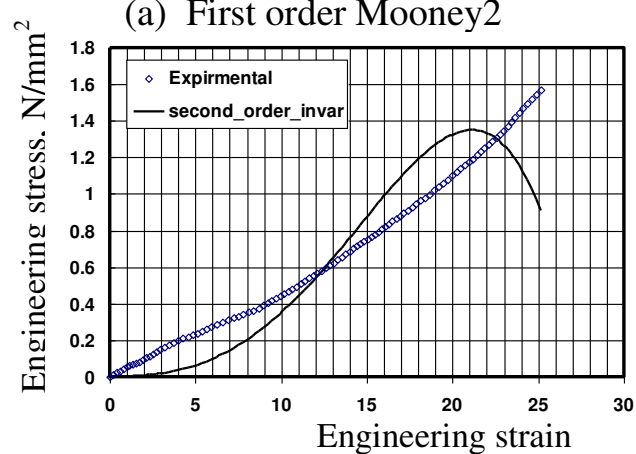

(c) Second order Mooney

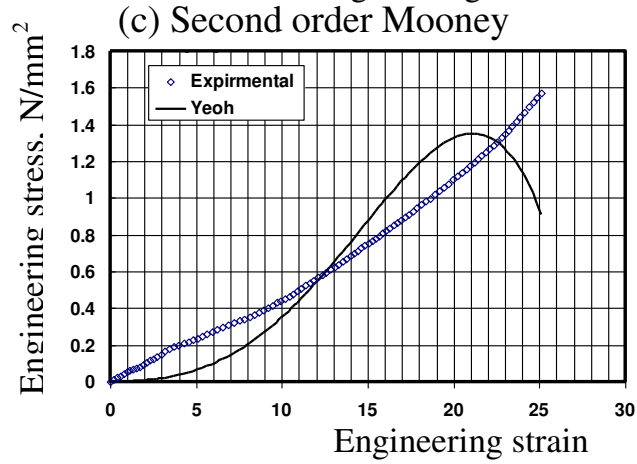

(e) the Yeoh model

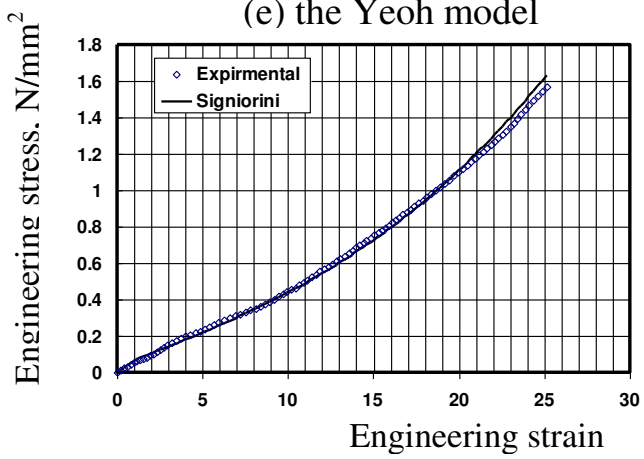

(g) Signiorini model

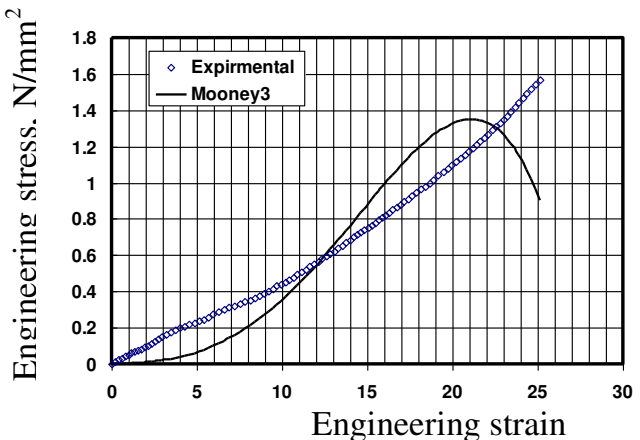

(b) First order Mooney3

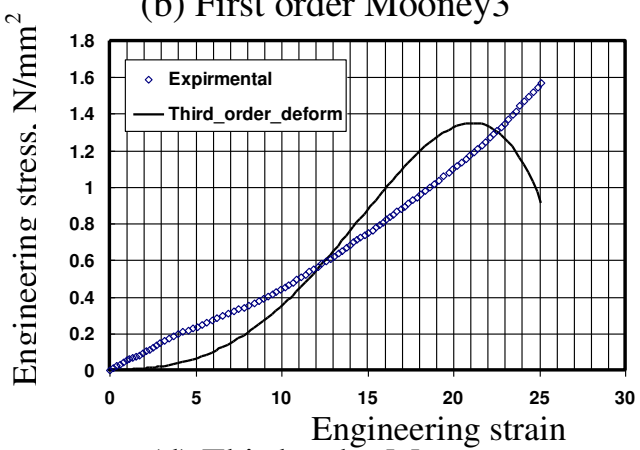

(d) Third order Mooney

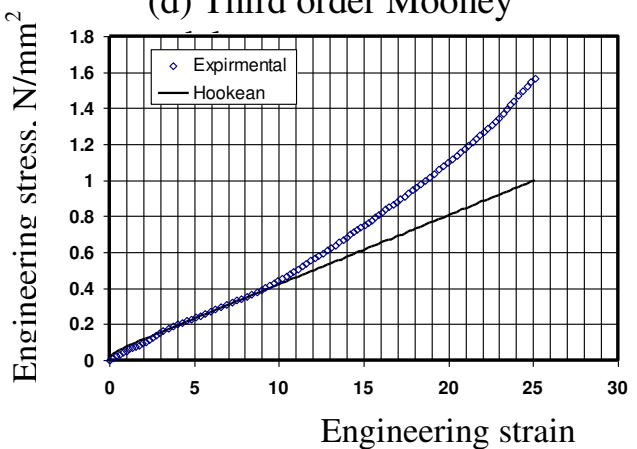

(f) Hookean model

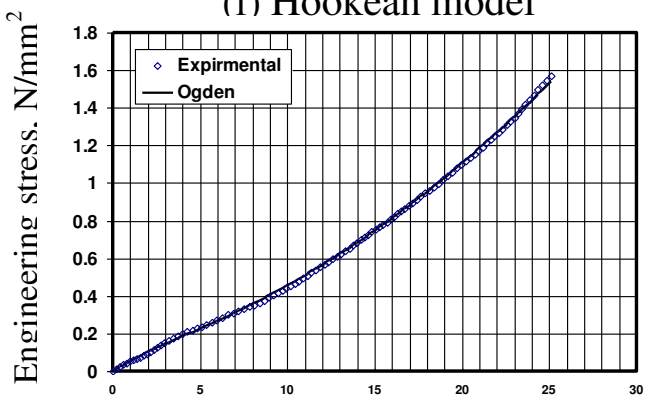

Engineering strain

(h) Ogden model 
Figures 5(a) - (h) show the curve fitting of the experimental data with the seven rubber material models, $\mathrm{CB} \%=30$.

Table 2 Scalar multipliers and relaxation time constants $(\mathrm{N}=4)$

\begin{tabular}{|l|c|c|c|c|c|c|c|c|}
\hline $\mathbf{C B} \%$ & $\delta^{1}$ & $\delta^{2}$ & $\delta^{3}$ & $\delta^{4}$ & $\lambda^{1}$ & $\lambda^{2}$ & $\lambda^{3}$ & $\lambda^{4}$ \\
\hline 0 & 0.006325 & 0.029177 & 0.080154 & 0.339067 & 1.229 .57 & 29241.4 & $1.9508 \mathrm{e} 6$ & $4.394 \mathrm{e} 6$ \\
\hline 20 & 0.0171617 & 0.058874 & 0.461272 & 0 & 551.261 & 7028.42 & $1.1792 \mathrm{e} 9$ & 0 \\
\hline 30 & 0.0255098 & 0.014975 & 0.054878 & 0.452448 & 210.439 & 1507.02 & 13991.6 & $9.201 \mathrm{e} 8$ \\
\hline 50 & 0.122576 & 0.008716 & 0.067445 & 0.407595 & 212.611 & 5254.25 & 253484 & $7.6176 \mathrm{e} 8$ \\
\hline 70 & 0.007025 & 0.05658 & 0.051784 & 0.251633 & 147.009 & 2375.16 & 16161.2 & $1.4454 \mathrm{e} 6$ \\
\hline
\end{tabular}

\subsection{Effect of CB loading and amount of experimental data on Ogden model constants}

A series of fits for Ogden model $(N=4)$ that used tension and compression information has been conducted. Figure 6 shows the effects of $\mathrm{CB} \%$ and amount of experimental data on the variation of Ogden model constants. Coefficients $\mu_{1}$ to $\mu_{4}$ are varying greatly with the increasing of percentage carbon black as well the type and amount of experimental data. For instance, when using only tension data for fitting, the coefficients $\mu_{1}$ to $\mu_{4}$ affected greatly at $30 \% \mathrm{CB}$, however they greatly differ at $50 \%$ $\mathrm{CB}$ when using compression data alone as shown in Fig.6 (a) and (b), respectively. Adding tension to compression had a strong influence on the quality of the fit and the coefficient is markedly changed in stable manner as shown in Fig. 6(c). This is because Ogden model is slightly compressible material model and is sensitive to compression data. Thus, the volumetric compression test is needed in addition to compression and tension tests in order to accurately model the response of rubber. Effect of CB \% on Bulk modulus $(\mathrm{K})$ and initial rigidity modulus (Go) are shown in Figs. 7. When using Ogden model, the bulk modulus needs to be input, although its magnitude is not critical. To satisfy the incompressibility condition, bulk modulus should be infinitely large, but needs to be 104 times greater than Go. Even though, the initial Go is useful indicator of the accuracy of the Ogden constants in the model.

\section{FE-ANALYSIS OF THE EFFECT OF FRICTION AND COMPARISON TO THE EXPERIMENTAL DATA}

\section{Compression Test}

The effect of friction between the compression loading platens and the specimen under test is examined by FE-simulation. The ASTM D 695, type 1 which is used in ASTM 575 Standard Test methods for rubber properties in compression was modeled and numerically strained. The test specimen was discredited into 960 quadratic eight node elements and 3-D large strain total Lagrange method was selected. The coefficient of 
friction was altered to see the effect of friction on the resulting stress-strain data. A coefficient of friction value of zero corresponds to a perfect state of simple uniaxial compression while friction coefficient equals 1 for glued condition. The shapes of deformed mesh of the compression specimen at friction coefficients $\mu=0$ and $\mu=1$ are shown in Figure. 8. Figure 9 shows the effect of friction condition on the calculated load/displacement curves of uniaxial compression test. From figures 8 and 9 , it is clear that friction condition significantly affects the overall deformation patterns as well as the calculated load displacement response. The effect of carbon black content, CB\%, on the response of the uniaxial compression test was simulated utilizing the material constants obtained from Ogden model and the results are shown in Figure 10. It is seen that even small levels of $\mathrm{CB} \%$ affect the measured stiffness i.e. increasing of $\mathrm{CB} \%$ would increase the force displacement response. In the uniaxial compression test, the error depends on friction which is unknown and varies as a function of the test material and the normal force. This error could be eliminated if the equal biaxial test is used because pure strain state required for hyperelastic constitutive models could be obtained [11]. Regardless to small errors (see Fig. 10) between experimental load/displacement response and FE analysis of uniaxial compression test, the Ogden model is sufficiently enough to regenerate the experimental data.

\section{CONCLUSIONS}

Material properties of Nitrile butadeine rubbers vary with carbon black percentage content. For constant CB\% experimental data, it is found that Ogden, Signiorini and first order Mooney2 give material models best fits; while the fits of the other five models are invariably poor. Therefore, the Ogden material model is chosen to represent the hyperelastic behavior of the NBR and to study the effects of CB\% and amount of experimental data on material constants of the NBR. The variation of Ogden model constants with CB\% is pronounced. Constants $\mu_{1}$ to $\mu_{4}$ are volatile when using tension or compression data alone, however values of $\mu_{1}$ to $\mu_{4}$ gradually change in a stable manner when using tension and compression data together for fitting. The values of $\mu_{4}$ are small and have little influence on computed stresses and deformation or the load /displacemen t curves. The Ogden model is more reliable predictor of NB rubber compared with those models which use strain invariants. Ogden model takes into consideration the volumetric change during loading and is sensitive to compression data. The predicted load/displacement of the uniaxial compressive test by FEA has close correlation with the experimental data. The mean constants of Ogden model could be used to predict NB rubber deformation to a reasonable accuracy and offer the best opportunity of their hyperelastic behaviors. Moreover, the viscohyperelastic behavior could be simply obtained by a multiplicative decomposition of Ogden model with a relaxation function in a Prony series. Scalar multipliers and relaxation time constants of the desired relaxation function for NBR with different $\mathrm{CB} \%$ have been already determined. 


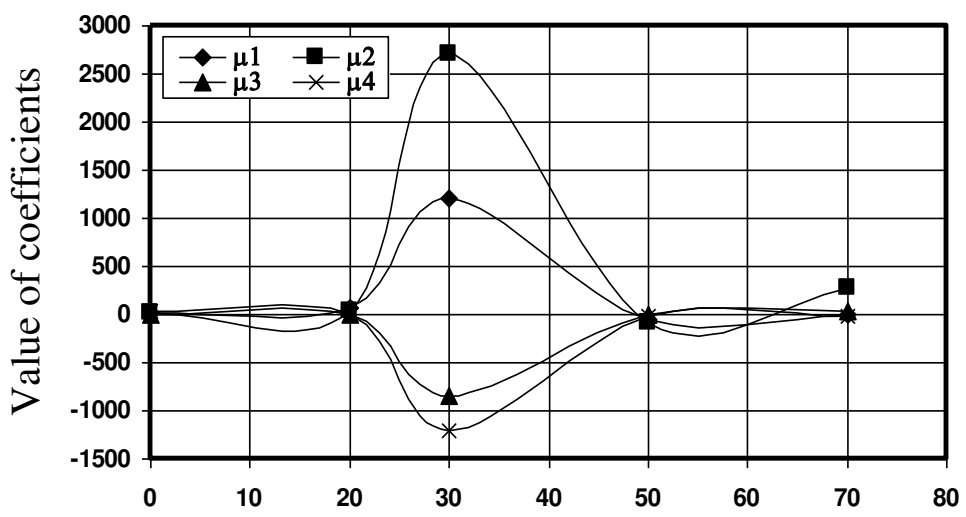

(a)

$\mathrm{CB} \%$

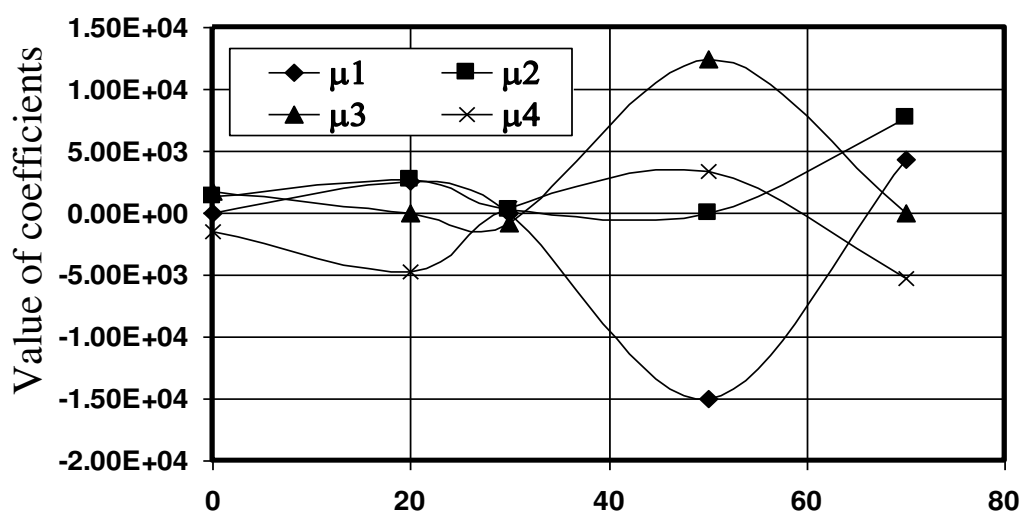

(b)

$\mathrm{CB} \%$

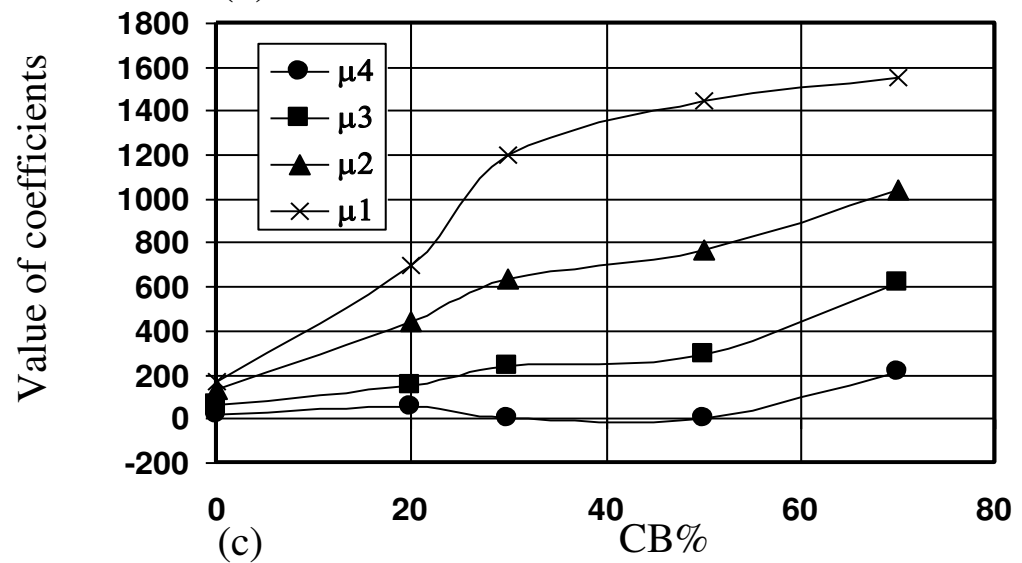

Figure 6 Effect of $\mathrm{CB} \%$ and amount of experimental data on Ogden model constants $\mathrm{N}=4$, (a) Tension, (b) compression, (c) Tension + Compression 

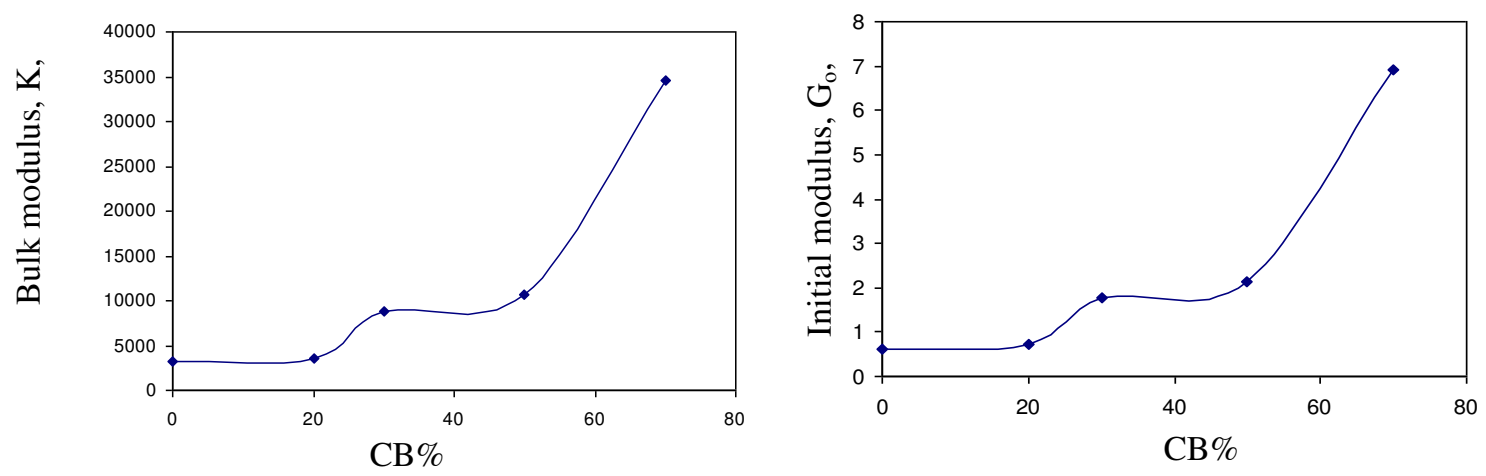

Figure 7 Effect of $\mathrm{CB} \%$ on bulk modulus and initial shear modulus of NBR material Ogden $N=4$, Tension data (No friction $\mu=0$, Glued condition $\mu=1$

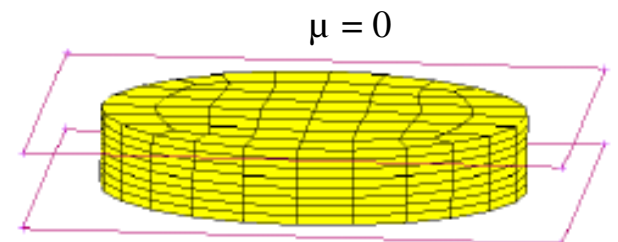

(a)

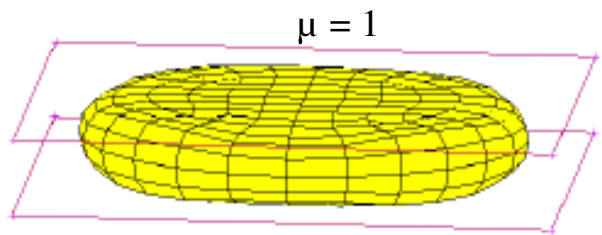

(b)

Figure 8 Geometries of deformed mesh of the compression specimen of $30 \% \mathrm{CB}$ at friction coefficients (a) $\mu=0$ and (b) $\mu=1$

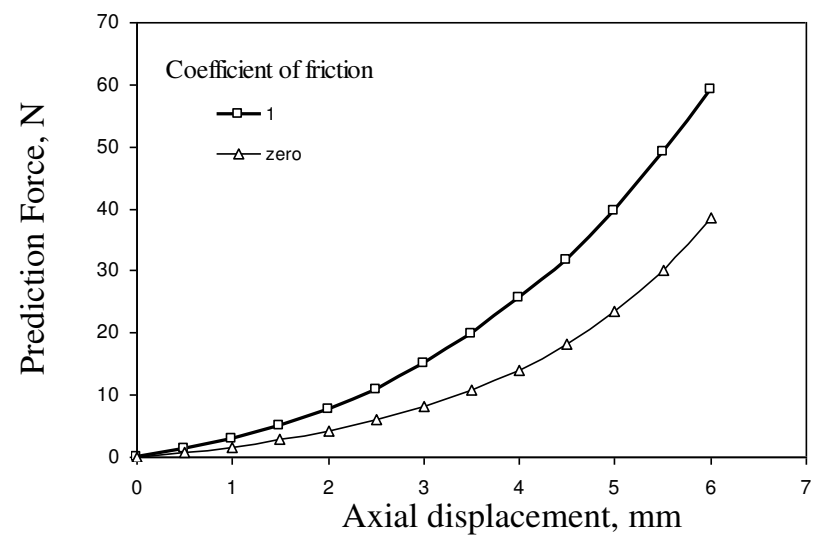

Figure 9 Effect of friction condition on force displacement response of uniaxial compression test of $30 \% \mathrm{CB}$ 


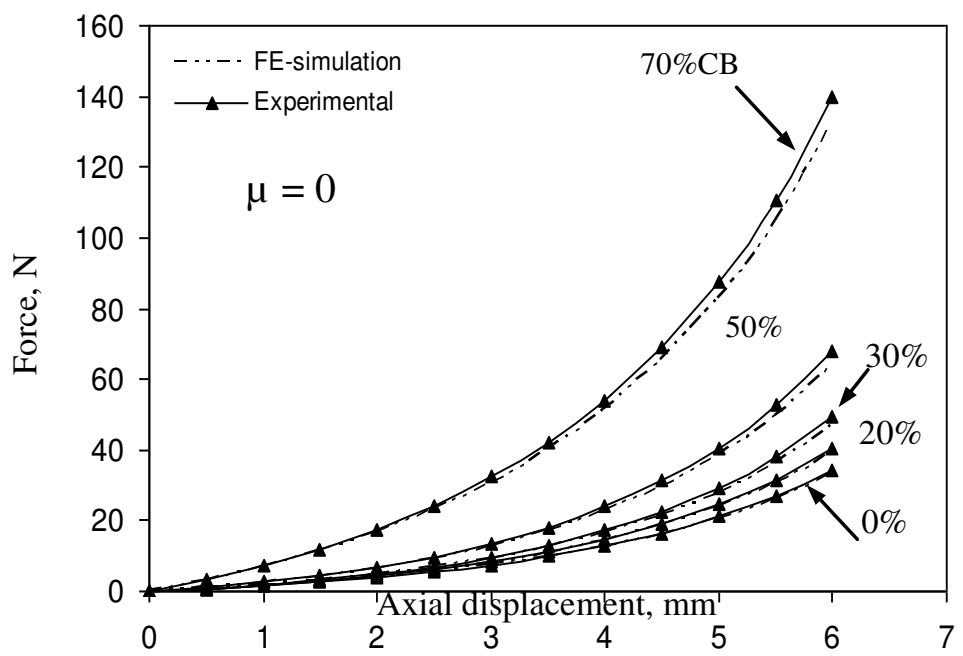

Figure 10 A comparison between experimental load/displacement response and FEanalysis of uniaxial compression test at different $\mathrm{CB}$ loading and $\mu=0$

\section{REFERENCES}

1. Milašienè D., Jankauskaitė V, Arcišauskaitè R. "Prediction of stress relaxation in laminated leather layers" Materials Science (MEDŽIAGOTYRA), Vol. 9(1), pp 73-79, 2003.

2. Abouel-kasem A., Lazarev S.O. "Micro elastoviscoplastic model of rubber and its usage for numerical analysis and design of parts", $\mathrm{IV}^{\text {th }}$ International Conference on Scientific and Technical Problems of Forecasting of Reliability and Durability of Designs and Methods of their solution, pp. 13-15, November 27-December 2, San Petersburg, Russia, 2000.

3. Fujii T. "Dynamic response of sandwich beams with an adhesive damping layer (generalized Maxwell model for a viscoelastic adhesive layer)" Int. J. Adhesion and Adhesives, Vol. 13, pp 201-209, 1993.

4. Sato K., Toda A. "Modeling of the peeling process of pressure-sensitive adhesive tapes with the combination of Maxwell elements" J. Phys. Soc. Japan, Vol. 73, PP 2135-2141, 2004.

5. ASTM D 412. "Standard test method for tension testing of vulcanized rubber" Philadelphia: Annual Book of ASTM Standards; 1958.

6. Mostafa A., Abouel-Kasem A., Bayoumi M.R., El-Sebaie M.G. "Insight into the effect of CB loading on tension, compression, hardness and abrasion properties of SBR and NBR filled compounds", Materials \& Design, Volume 30, Issue 5, May 2009, Pages 1785-1791.

7. ASTM D 695. "Standard test method for compression properties of rigid plastics" Philadelphia: Annual Book of ASTM Standards; 1958.

8. ASTM D 676. "Standard test method for indentation of rubber by means of a durometer" Philadelphia: Annual Book of ASTM Standards; 1958. 
9. Mostafa A., Abouel-Kasem A., Bayoumi M.R., El-Sebaie M.G., "On the influence of CB loading on the creep and relaxation behavior of SBR and NBR rubber vulcanizates", J Materials \& Design, Volume 30, 2009, Pages 2721-2725

10. Spencer A. J. M., "Continuum Mechanics", Longman Group Ltd., London (1980)

11. Jim Day and Kurt Miller, "biaxial and compression testing of rubbers", MARC v5.2, User manual 2005.

\section{حساب ثوابت المواد لمطاط النيتريل بوتادين ذو نسب مختلفة من أسود الكريون باستخدام المحاكاة بطريقة العنصر المحدود والتجارب المعملية د. أحمد أبو القاسم أحمد د. محسن عبد النعيم حسن د. محمود أحمد عبد الله الشريف}

تستعمل اضافات أسود الكربون لتحسين الخواص الميكانيكية للمطاط المعروف بنيتريل بوتادين (NBR) • ويلقى تصميم الأجزاء المطاطية صعوبة كبيرة نتيجة لعدم المعرفة الكافية لخواص وسلوك المطاط.

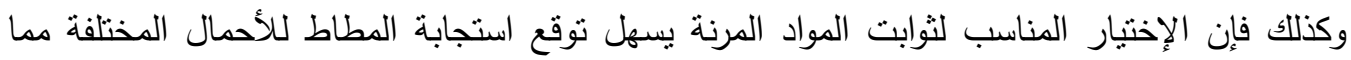
يجعل الأجزاء المطاطية مصممة بشكل جيد من الناحية الإقتصادية. يقدم هذا البحث دراسة عملية وتحليلية لتحديد خواص وسلوك مطاط النيتريل بوتادين (NBR) ذو نسب مختلفة من أسود الكربون (CB\%) والنى تثمل اختبارات الثد والضغط والإرتخاء. وقد تم عمل دراسة تحليلية لستة نماذج مختلفة تمثل المواد المطاطية بإستخدام التجارب المعطلية وتم تحديد ثوابت كل نموذج على حده. وبمقارنة سلوك النماذج، تبين أن نموذج أودن (Ogden) يعطى أفضل نموذج بالمقارنة مع السلوك العملى للمواد

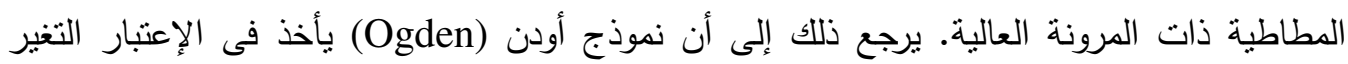

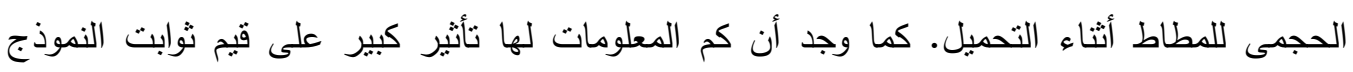
(نموذج أودن). كما وجد أيضا أن قيم ثوابت نموذج أودن (Ogden) تعتمد على نوعية المعلومات

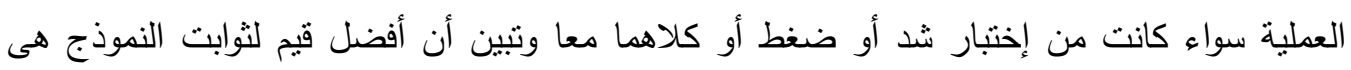

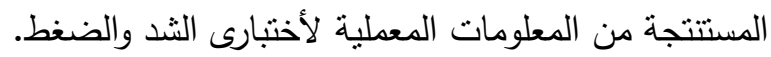
تنين من المقارنة العملية والتحليلية بأستخدام المحاكاة بطريقة العنصر المبارية المحدود باستخدلم نموذج أودن

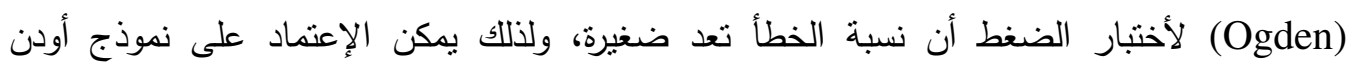

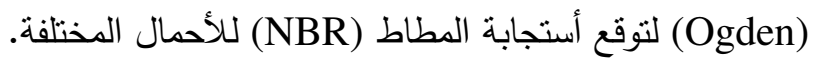

